PROCEEDINGS OF THE $30^{\text {th }}$ European Symposium on Computer Aided Process Engineering (ESCAPE30), May 24-27, 2020, Milano, Italy

(C) 2020 Elsevier B.V. All rights reserved.

\title{
Integrated Planning of Industrial Gas Supply Chains
}

\author{
Yena Lee $^{a}$, Alba Carrero-Parreño ${ }^{a}$, Lazaros G. Papageorgiou ${ }^{a,}$, \\ Sivaraman Ramaswamy ${ }^{\mathrm{b}}$, Jose M. Pinto ${ }^{\mathrm{b}}$ \\ ${ }^{a}$ Centre for Process Systems Engineering, Department of Chemical Engineering, UCL \\ (University College London), Torrington Place, London WC1E 7JE, UK \\ ${ }^{b}$ Linde plc., 10 Riverview Drive, Danbury CT 06810, United States \\ l.papageorgiou@ucl.ac.uk
}

\begin{abstract}
In this work, we propose a Mixed Integer Linear Programming (MILP) model for optimal planning of industrial gas supply chain, which integrates supply contracts, production scheduling, truck and rail-car scheduling, as well as inventory management under the Vendor Managed Inventory (VMI) paradigm. The objective used here is minimisation of the total operating cost consisting of purchasing of raw material, production, and transportation costs by trucks/rail-cars so as to satisfy customer demands over a given time horizon. The key decisions for production sites include production schedule and purchase schedule of raw material, while the distribution decisions involve customer to plant/depot allocation, quantity transported through rail network, truck delivery amounts, and times. In addition, a relaxation approach is proposed to solve the problem efficiently. An industrial case study is evaluated to illustrate the applicability of the integrated optimisation framework.
\end{abstract}

Keywords: Integrated supply chain planning, discount contract model, rail-car and truck scheduling, relaxation approach

\section{Introduction}

The optimisation of supply chain planning for the industrial gas business is a challenge when the supply chain structure integrates multiple decisions such as: supply contracts, inventory management, production and distribution scheduling, etc. As the level of detail increases, it becomes more difficult to optimally solve the model due to its complexity. However, optimal decisions considering a coordinated industrial gas supply chain have significant benefits (Marchetti et al., 2014). In their research, potential cost savings were identified with coordination between production and distribution in industrial gas supply chain. Nevertheless, expensive computational cost is required when dealing with large size examples. Recently, some efforts have been made to tackle this limitation. You et al. (2011) developed a mixed integer linear programming model which considers distribution and inventory decisions of industrial gas supply chain planning simultaneously. They also proposed two different approaches to solve the large-scale instances. The first one is based on a two-level decomposition method and the second one is based on a continuous approximation method. Additionally, Zamarripa et al. (2016) proposed a rolling horizon decomposition approach for full space optimisation problem which coordinate production-distribution decisions, and Zhang et al. (2017) proposed an MILP model and an iterative heuristic approach for the multiscale production routing problem which integrates production, distribution, and inventory decisions. 
In this work, we investigate a problem of optimal integrated production and distribution planning that reliably produces $\mathrm{CO}_{2}$ from a number of plants (and sourced from external third-party suppliers) and distributes high quality $\mathrm{CO}_{2}$ product to a network of depots and customers. The problem is formulated as a mixed integer linear programming (MILP)model which can simultaneously deal with purchase contracts, inventory management, production, and truck/rail-car scheduling. Furthermore, we present a relaxation approach to handle the computational complexity of a large-scale industrial problem.

\section{Problem Definition}

This study considers an existing $\mathrm{CO}_{2}$ supply chain network (schematized in Figure 1) located in the U.S. which comprises of external $\mathrm{CO}_{2}$ suppliers, production plants, depots, third-party suppliers, and customers. The crude $\mathrm{CO}_{2}$ is purchased from external suppliers by discount contracts and transformed into high purity $\mathrm{CO}_{2}$ in the plants. This pure $\mathrm{CO}_{2}$ can also be sourced from third-party suppliers. The distribution between different locations to satisfy the customers' demand is guaranteed via rail-cars or trucks. The railcars can distribute the $\mathrm{CO}_{2}$ product from plants/third-parties to depots using existing rail infrastructure, and the trucks from the plants, depots and/or third parties to the customers. The customers' demand is controlled by the Vendor Managed Inventory (VMI) paradigm. Under this policy, each customer inventory level is monitored to deliver the product when it reaches close to the minimum level.

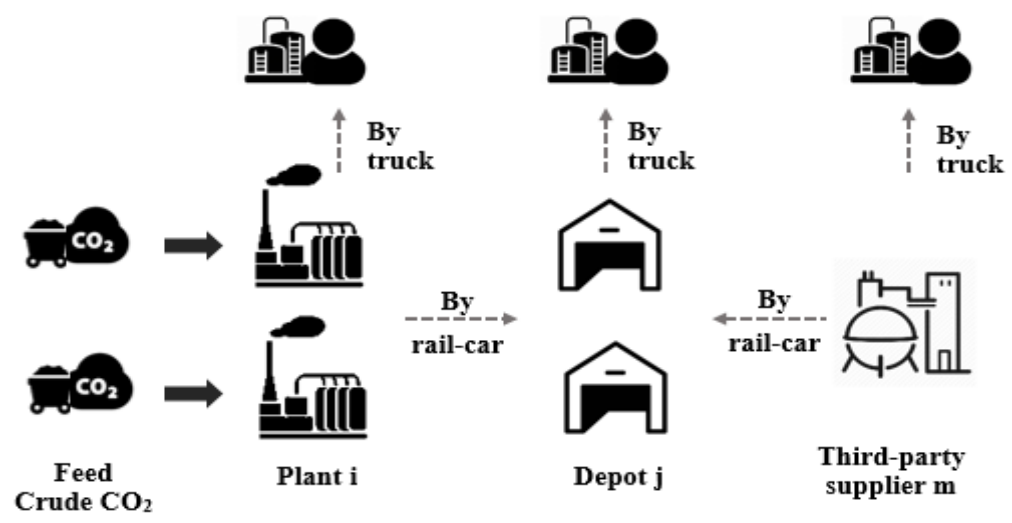

Figure 1. Network structure for the $\mathrm{CO}_{2}$ supply chain planning problem

The problem can be stated as follows:

Given (a) for each plant: its location, maximum production capacities, and corresponding production and crude $\mathrm{CO}_{2}$ purchasing costs; (b) for each depot: its location; (c) for each third-party supplier: its location, maximum purchasing amount, and purchasing costs; (d) for customers: their locations, and daily consumption rates; (e) for inventories: initial levels, minimum levels, and maximum levels; (f) for trucks and railcars: its loading capacities, maximum quantities, and transfer unit costs; 
Determine (a) Production schedule; (b) Purchasing schedule of crude $\mathrm{CO}_{2}$ and $\mathrm{CO}_{2}$ product from external suppliers and third party suppliers, respectively; (c) Allocation of plant/depot/third party to customer; (d) Rail-car schedule;

So as to minimise the overall cost of integrated $\mathrm{CO}_{2}$ supply chain planning by satisfying customer demands over a given time horizon.

\section{Mathematical Framework}

The overall problem is formulated as a Mixed Integer Linear Programming (MILP) model which integrates supply contracts, truck and rail-car scheduling, as well as inventory management under the Vendor Managed Inventory (VMI) paradigm. A brief outline of some of the model constraints is next given.

min. $T C^{\text {total }}$

$$
T C^{\text {total }}=T C^{\text {raw }}+T C^{\text {prod }}+T C^{\text {st }}+T C^{o s}+T C^{\text {rail }}+T C^{\text {truck }}
$$

Eq. (1) is the objective function and considers the minimization of total cost which consists of crude $\mathrm{CO}_{2}$ cost, production cost, plant start-up cost, product $\mathrm{CO}_{2}$ purchasing cost, and transportation cost via rail-car and truck.

$$
\begin{array}{ll}
T C^{\text {raw }}=\sum_{i n} C_{i n}^{\text {raw }} F_{i n} & \\
\sum_{n} F_{i n}=\sum_{t} R_{i t} & \forall i \\
\left(\lambda_{\text {in }}-\lambda_{i, n-1}\right) y_{i, n+1} \leq F_{\text {in }} \leq\left(\lambda_{i n}-\lambda_{i, n-1}\right) y_{i n} & \forall i, n=\{1,2, \ldots N-1\} \\
F_{\text {in }} \leq M y_{\text {in }} & \forall i, n=N \\
y_{\text {in }} \geq y_{i, n+1} & \forall i, n=\{1,2, \ldots N-1\}
\end{array}
$$

Eq. (3)-(7) represent a discount contract model for crude $\mathrm{CO}_{2}$. The proposed discount contract model follows the model published by Park et al. (2006). In their formulation, the purchasing cost is decided by a binary variable depending on both cost region $n$ and time period $t$. However, as in our problem the discount is applied to the total cumulative purchasing amount, it is reformulated considering a non-time-dependent binary variable. Eq. (3) calculates the total cost for crude $\mathrm{CO}_{2}$ which depends on the purchased amount in the cost region $n\left(F_{i n}\right)$, and the corresponding cost for plant $i\left(C_{i n}^{r a w}\right)$. Eq. (4) indicates that the total purchased amount in each cost region is equal to the sum of the purchased amount in each time period $t$. Eq. (5) determines the amount corresponding on each cost region; i.e. $y_{i n}$ is equal to 1 when the total purchased amount $\sum_{t} R_{i t}$ is in the cost region $n$. Here, $\lambda_{\text {in }}$ is the breakpoint of cost region $\mathrm{n}$, where the price is reduced when the total cumulative purchasing amount during a time horizon excess the breakpoint. Eq. (6) restricts the amount in the last lost region $(n=N)$; i.e. $F_{i N}$ has to be lower than the $\mathrm{M}$ value. 
Finally, Eq. (7) is a logical relationship which avoid the selection of intermediate cost regions.

$$
\begin{gathered}
\text { TC } C^{\text {truck }}=\sum_{s \in\{I, J, M\}} \sum_{k} \sum_{l \in l_{\text {Truck }}} \sum_{t} C^{\text {truck }} D_{s k} Q_{s k l t} \\
\sum_{l \in l_{\text {Truck }}} \sum_{k} \alpha_{s k} Q_{\text {sklt }} \leq N T_{s}^{\text {max }} \text { Cap }^{\text {truck }} \quad \forall t, s \in\{I, J, M\}
\end{gathered}
$$

Eq. (8)-(9) state the relaxed formulation for the truck scheduling problem to estimate the trucking cost and allocate plants/depots/third-parties to customers without considering the detailed scheduling. By using this formulation, the discrete variables associated with the detailed truck scheduling are relaxed; therefore, the computational efficiency is improved when dealing with a large number of customers, plants and time horizon. Eq. (8) calculates the transfer cost by trucks departing from plants $i$, depots $j$, and third-parties $m$. The truck cost is based on the unit transfer cost $\left(C^{\text {truck }}\right)$, travelling distance $\left(D_{s k}\right)$, and loading amount $\left(Q_{s k l t}\right)$. Constraint (9) limits the total product amount transferred by trucks. Because trucks can make multiple trips per time period $t$, not only the loading capacity but also the number of the multiple trips should be considered to limit the total amount transferred during a time period $t$. However, the complexity of the model increases if integer variables are introduced to consider the number of the multiple trips. Here, the duration of the round-trip between the locations $\left(\alpha_{s k}\right)$, which is formed as a fraction of a time period, is introduced to approximate the total transferred amount by the multiple trips instead of introducing the integer variables. By using the fraction of travelling time $\left(\alpha_{s k}\right)$, all the integer variables can be relaxed into continuous variables $\left(Q_{s k l t}\right)$. Finally, the total amount transferred by trucks during a time period $t$ is restricted by the loading capacity ( Cap $^{\text {truck }}$ ), and the number of trucks available at each plant, depot, and third-party $\left(N T_{s}^{\max }\right)$.

\section{Case Study and Results}

The proposed model is applied for a large-scale industrial supply chain planning problem given by Linde which includes $700+$ customers, total $30+$ of plants, depots, transshipments, third-parties, and one month discretised into 30 days. To compare the efficiency and validity of the relaxation approach, the case study is solved with the proposed MILP model $\left(\mathrm{M}^{\mathrm{R}}\right)$, which includes the approach and the integrated one $(\mathrm{M})$, which involves the discrete variables to indicate the multiple trips made by trucks. Both models are implemented into GAMS software and solved using Gurobi 8.1.0 on Intel 3.60 GHz, 16.0 GB RAM computer.

Table 1. Optimal solution and computational performance

\begin{tabular}{lcc}
\hline Model & $\mathrm{M}$ & $\mathrm{M}^{\mathrm{R}}$ \\
\hline Equations & 252,364 & 140,869 \\
Continuous variables & 138,253 & 138,253 \\
Discrete variables & 653,156 & 5,411 \\
Optimality gap [\%] & 5 & 1 \\
CPU time [s] & 144,371 & 145 \\
Total cost [M\$] & 5.73 & 5.25 \\
\hline
\end{tabular}


Table 1 describes the problem size, optimal solution and computational performance of the rigorous and relax model. It can be observed that the case study cannot be solved with the rigorous formulation in an acceptable computational time since the large number of discrete variables. It requires $40 \mathrm{~h}$ to reach an optimal solution with $5 \%$ of optimality gap. Conversely, the CPU time significantly decreases solving the relaxed formulation as the number of discrete decisions is reduced to 5,411. This enables the model to handle the large-scale problem by reducing computational time dramatically. Additionally, to validate the optimal solution, the gaps of the optimal costs generated by model $\mathrm{M}$ and model $\mathrm{M}^{\mathrm{R}}$ are presented in Table 2 . The table shows that these gaps are within $5 \%$ except for the start-up and third-party cost, but they only account for $1 \%$ and $2 \%$ of the total cost, respectively as it can be shown in the total cost breakdown of Figure 2.

Table 2. Gaps between optimal solution from the model $\mathrm{M}$ and model $\mathrm{M}^{\mathrm{R}}$

\begin{tabular}{lcccccc}
\hline Cost breakdown & $T C^{\text {raw }}$ & $T C^{\text {rod }}$ & $T C^{\text {st }}$ & $T C^{\text {os }}$ & $T C^{\text {rail }}$ & $T C^{\text {truck }}$ \\
\hline Gap [\%] & 1 & 0 & 14 & 0 & 5 & 2 \\
\hline
\end{tabular}

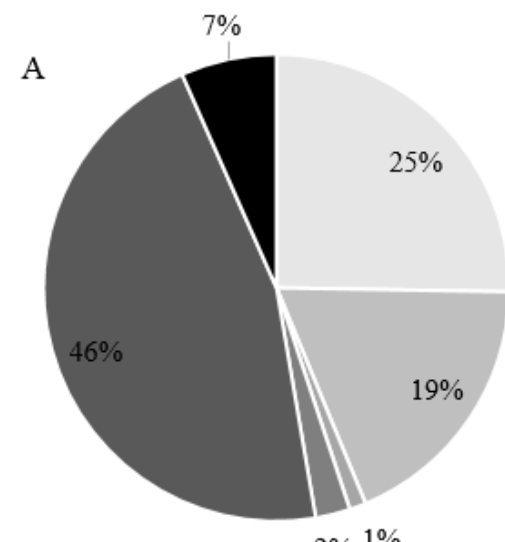

$2 \% 1 \%$

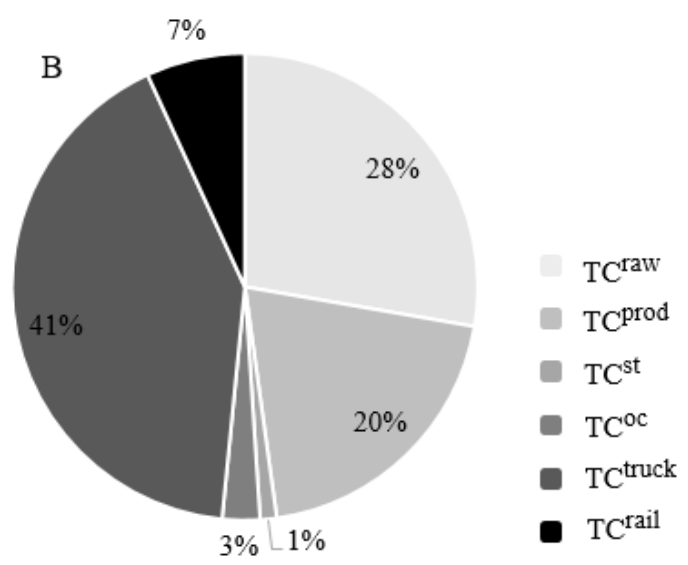

Figure 2. Total cost breakdown of (A) the model $\mathrm{M}$ and (B) the model $\mathrm{M}^{\mathrm{R}}$

In the figure, each breakdown cost of total cost obtained from each model account for almost the same percentage which means that the relaxed approach proposed can predict optimal costs without significant degradation of solution quality.

Figure 3 and Figure 4 illustrate part of the production and rail-car scheduling results gained from model $\mathrm{M}^{\mathrm{R}}$. In the production scheduling result, each value in the colored cells shows the production amount during a time period $t$. In the rail-car scheduling result, the solid cells represent one-way trip, whereas the vertical striped cells represent returning trip. The figures reveal that the proposed model is capable of providing detailed solutions for the production scheduling problem and rail-car scheduling problem without considering detailed truck scheduling. 


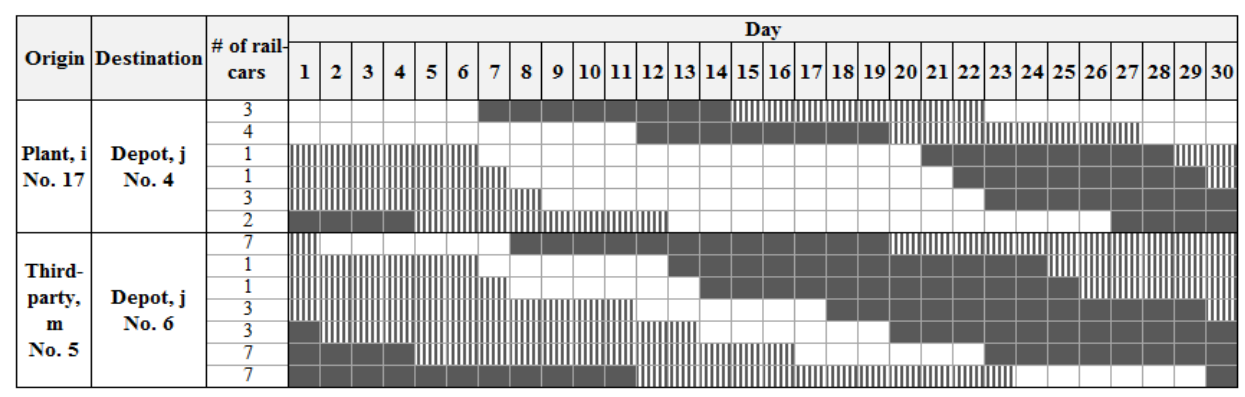

Figure 3. Gantt chart for rail-car schedule

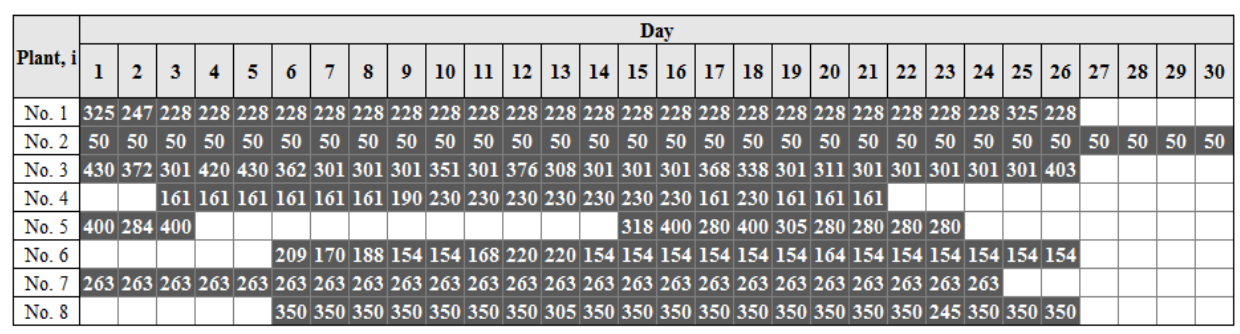

Figure 4. Production schedule

\section{Conclusions}

This work has introduced an MILP formulation which considers supply contracts, inventory management, production, rail-car and truck scheduling simultaneously. To handle the complexity of the integrated problem, a relaxation approach is applied in the truck scheduling problem where discrete variables associated with the detailed truck scheduling are relaxed to continuous variables. The proposed strategy successfully solve a real large-scale industrial gas supply chain planning case study given by Linde. The results prove that the proposed approach has the capability of finding an optimal solution without significant degradation of quality, as well as high computational efficiency.

\section{References}

P. A. Marchetti, V. Gupta, I. E. Grossmann, L. Cook, P.-M. Valton, T. Singh, T. Li, J. André, 2014. Simultaneous production and distribution of industrial gas supply-chains. Computers \& Chemical Engineering 69, 39-58.

M. Park, S. Park, F. D. Mele, I. E. Grossmann, 2006. Modeling of purchase and sales contracts in supply chain optimization. Industrial \& Engineering Chemistry Research 45 (14), 5013-5026.

F. You, J. M. Pinto, E. Capón, I. E. Grossmann, N. Arora, L. Megan, 2011. Optimal distributioninventory planning of industrial gases. i. fast computational strategies for large-scale problems. Industrial \& Engineering Chemistry Research 50 (5), 2910-2927.

M. Zamarripa, P. A. Marchetti, I. E. Grossmann, T. Singh, I. Lotero, A. Gopalakrishnan, B. Besancon, J. André, 2016. Rolling horizon approach for production-distribution coordination of industrial gases supply chains. Industrial \& Engineering Chemistry Research 55 (9), 26462660.

Q. Zhang, A. Sundaramoorthy, I. E. Grossmann, J. M. Pinto, 2017. Multiscale production routing in multicommodity supply chains with complex production facilities. Computers \& Operations Research 79, 207-222. 